\title{
Estrategia imperial y crédito local. El archipiélago de Malvinas en la construcción de la frontera hispánica (1767-1774)
}

por

Carolina Martínez ${ }^{1}$

CONICET-UNSAM
Martín L. E. Wasserman ${ }^{2}$

CONICET-UBA

El presente artículo indaga el rol del archipiélago de Malvinas en la reconfiguración del espacio hispanoamericano desde 1767. Para ello, se articulan tres variables de análisis: la importancia geopolítica de las islas Malvinas a escala global, su lugar en la redefinición de la frontera imperial de la monarquía española, y el papel que los actores económicos del Río de la Plata tuvieron en la colonización del archipiélago. Empleando documentación política, cartográfica y fiscal, este trabajo demuestra que la consolidación de las fronteras que la Monarquía precisaba asegurar confluyó con los intereses de las oligarquías financieras locales.

Palabras Clave: islas Malvinas; monarquía española; geopolitica; finanzas; siglo XVIII.

Cómo Citar Este Artículo / Citation: Martínez, Carolina y Wasserman, Martín L. E., "Estrategia imperial y crédito local. El archipiélago de Malvinas en la construcción de la frontera hispánica (1767-1774)", Revista de Indias, LXXXI/283 (Madrid, 2021): 703-728. https://doi.org/10.3989/revindias.2021.020.

INTRODUCCIÓN. LAS ISLAS MALVINAS DESDE TRES ESCALAS DE OBSERVACIÓN

En 1764, bajo los auspicios de Louis-Antoine de Bougainville y su primo Michel-François Bougainville de Nerville, la Compañía francesa de Saint-Malo

1 cmartinez79@gmail.com, carolina.martinez@unsam.edu.ar, ORCIDiD: https://orcid.org/00000002-5692-0995

2 mwasserman@filo.uba.ar, ORCID iD: http://orcid.org/0000-0001-9414-7449 de uso y distribución Creative Commons Reconocimiento 4.0 Internacional (CC BY 4.0). 
estableció el primer asentamiento permanente en las islas Malvinas ${ }^{3}$. La colonia de 115 habitantes, sin embargo, debió ser levantada tres años después, cuando como corolario del Tratado de París (1763) y de la pérdida de muchos de sus territorios en América la Corona francesa conviniera en la restitución del archipiélago a España en reconocimiento de su soberanía sobre las islas. Tras acordarse el pago de una compensación a la Compañía de Saint-Malo por parte de la Corona española, la cesión de las islas se produjo el 1 de abril de 1767 de manos del propio Bougainville, quien regresó a ellas para recoger a los colonos que no deseaban permanecer allí una vez realizada la restitución. Poco antes, a través de la real cédula de 1766, Carlos III había creado la sub-gobernación de Malvinas, que dependería del gobernador de Buenos Aires hasta la creación del Virreinato del Río de la Plata en 1776. A partir de su traspaso y hasta 1770, las islas estuvieron bajo la jurisdicción del gobernador de Buenos Aires Francisco de Paula Bucarelli, mientras que su gobernación subordinada y administración sobre el terreno fueron asignadas a Felipe Ruiz Puente hasta $1773^{4}$.

El análisis de los ingresos y egresos del Real Situado de Buenos Aires y de los registros cartográficos sobre las islas producidos entre 1766 y 1774 revela que, en vísperas de su traspaso a manos españolas y en los años que siguieron a su restitución, las Malvinas cobraron una importancia estratégica sin precedentes para España ${ }^{5}$. En principio, los ingresos y egresos del Real Situado de Buenos Aires registrados entre 1766 y 1774 dan cuenta del creciente lugar otorgado a las islas dentro de las prioridades de la región. A su vez, las detalladas cartografías del archipiélago recuperado, que actualmente se conservan en el Archivo General de Indias, Sevilla, evidencian no sólo el afán de medición y conocimiento del mundo propio del período ilustrado sino el valor geoestratégico que la Corona española otorgó a las islas en un contexto de competencia inter-imperial signado por profundas reformas administrativas en sus territorios americanos. Sin duda, desde el establecimiento de la colonia proveniente de Saint-Malo (1763-1767) y la fundación del Puerto Egmont por parte de Lord Byron en 1765, la presencia de franceses e ingleses en las islas fue percibida como una clara amenaza a las posesiones insulares, pero sobre todo continentales de los borbones españoles en los mares del Sur.

${ }^{3}$ La colonia se estableció en el Puerto de Saint-Louis (fundado por Bougainville en 1764), en la región noreste de la isla que los españoles llamarían luego Soledad. Véase Pernety, 2012: 239-240.

${ }^{4}$ Caillet-Bois, 1961, vol. 2: 31. Martínez, 2017: 3.

5 Para un análisis pormenorizado del cambio de estatuto atravesado por el archipiélago de Malvinas y el crecimiento de su importancia geopolítica una vez producida su restitución véase Barriera, 2019. 
En función de lo antedicho, el presente artículo tiene por objetivo indagar en torno al valor asignado a las islas Malvinas en la reconfiguración del espacio colonial hispano a partir de su restitución por parte de Francia en 1767. La documentación política, económica y cartográfica relativa a las islas una vez restituidas será examinada en función de tres variables de análisis: a) su importancia geopolítica a escala global, b) su lugar en la redefinición de la frontera imperial de la monarquía católica y c) el rol condicionante que las oligarquías locales tuvieron en la colonización de las islas. En relación con este último punto, se propone que, para desplegar sus propósitos defensivos en sus territorios australes, la Corona dependió, no sólo de su capacidad para movilizar los fondos de la Hacienda americana con fines defensivos, sino de la capacidad financiera de los actores económicos del Río de la Plata. A partir de 1767, Buenos Aires se presentó como el eje articulador de una política imperial necesariamente imbricada en la escena local.

\section{LA RECONFIGURACIÓN DEL ORDEN IMPERIAL EN AMÉRICA: LA FIRMA DEL Tratado de París (1763)}

Todo análisis de la importancia de las islas Malvinas a escala global exige analizar la reconfiguración del orden geopolítico americano a raíz de la firma del Tratado de París en 1763. En lo que refiere a sus efectos en América septentrional, la derrota de Francia implicó la cesión de todos sus territorios a manos de los ingleses. Tal como establecía el propio Luis XV en las primeras páginas del tratado:

Su Majestad Cristianísima renuncia a todas las pretensiones que alguna vez tuvo o pudiera haber tenido sobre Nueva Escocia o la Acadia, en todas sus partes y la garantiza en su totalidad, y con todas sus dependencias, al Rey de Gran Bretaña; por otra parte, su Majestad Cristianísima cede y garantiza a dicha Majestad británica, en pleno derecho de propiedad, el Canadá con todas sus dependencias, así como la isla del Cabo Bretón y todas las otras islas y costas en el golfo y río San Lorenzo, y en general todo lo que depende de dichos países, tierras, islas y costas, junto con la soberanía, propiedad, posesión y todos los derechos adquiridos mediante Tratados o de otra forma... ${ }^{6}$

La obtención de dichos territorios por parte de Gran Bretaña marcaría el inicio de su hegemonía mundial ${ }^{7}$, provocando como corolario un cambio de estrategia por parte de las potencias derrotadas. En el caso de Francia, la

\footnotetext{
${ }^{6}$ Luis XV, 1763: 10. La traducción es nuestra.

7 Zusman, 1999. Bayly, 1989: 98.
} 
pérdida de los territorios mencionados impactó en la política exterior impulsada por la Corona en los años siguientes. Una vez firmada la paz, las medidas tomadas por el Duque de Choiseul, designado secretario de Estado de Guerra y de Marina en 1761, reflejaron en hechos concretos el cambio estratégico de la Corona ${ }^{8}$. Tal como ha señalado Andrés Freijomil, entre 1761 y 1770, Choiseul se encargó de reorganizar la educación de los oficiales, centralizar el reclutamiento y sumar 60 navíos de línea a la flota francesa ${ }^{9}$. Una de las consecuencias más notables de este conjunto de medidas fue el aumento de las navegaciones transoceánicas organizadas bajo patrocinio real, que tuvieron por objetivo compensar las pérdidas económicas en América septentrional y contrarrestar el avance inglés en ultramar ${ }^{10}$. Las exploraciones por los mares del Sur, que redundarían en el asentamiento de la colonia de SaintMalo en las islas Malvinas y en el viaje de circunnavegación emprendido por Bougainville (1766-1769) una vez realizado su traspaso resultaron, sin duda, los emprendimientos más significativos en términos de expansión.

En lo que se refiere a España, producto de sus alianzas con los borbones franceses para luchar contra Gran Bretaña, la casa de Borbón española también sufrió las consecuencias de la derrota. En principio, el tercer Pacto de Familia, firmado por ambas casas en $1761^{11}$, había involucrado a una España (no del todo preparada) en la Guerra de los Siete Años. Una vez finalizado el conflicto bélico, la derrota de Francia implicó para Carlos III la pérdida de La Florida, el fuerte de San Agustín y la bahía de Pensacola a manos de Gran Bretaña $^{12}$. A modo de compensación, Francia cedió una parte de la Luisiana y convino en restituir las islas Malvinas, que habían sido ocupadas por la compañía de Saint-Malo poco después de firmada la paz en París ${ }^{13}$. Además de los efectos del Tratado de París en la organización territorial de las colonias americanas, su firma también llevó a la revisión de los criterios jurídicos de posesión sobre los que se habían asentado los dominios coloniales en América hasta entonces. Tal como ha señalado Perla Zusman, fue en este período que, frente a los criterios de reconocimiento y ocupación defendidos por In-

${ }^{8}$ Fradera, 2018: 27.

9 Bougainville, 2005: 27.

${ }_{10}$ Paredes, 2011: 146. Véase también Groussac, 1936: 115.

${ }_{11}$ El tercer Pacto de Familia fue firmado a instancias del Duque de Choiseul y del Marqués de Grimaldi, gestores de los intereses de los reinos de Francia y España, respectivamente. En él, los borbones Luis XV y Carlos III se comprometían a apoyarse mutuamente ante un eventual conflicto o ataque externo.

12 Bougainville, 2005: 27.

${ }^{13}$ Los acuerdos establecidos entre los respectivos ministros de Carlos III y Luis XV garantizaron una restitución en relativos buenos términos. Groussac, 1936: 124. 
glaterra y Francia desde sus primeras incursiones en la carrera ultramarina, se produjo el debilitamiento de los principios papales ${ }^{14}$. En consecuencia, la Corona española debió implementar nuevas medidas para proteger territorios que jurídicamente poseía, pero no necesariamente ocupaba, como era el caso de la región patagónica e islas aledañas en la frontera sur de la América meridional. Ahora bien, si el cambio en su estrategia imperial respondía al advenimiento de un nuevo criterio jurídico, también se sustentaba en los intentos concretos de ocupación realizados por las Coronas inglesa y francesa en sus territorios ultramarinos.

\section{La Geopolítica en los MÁRgenes: el archipiélago de Malvinas y LA MONARQUÍA ESPAÑOLA ENTRE 1764 y 1776}

En el caso específico de Malvinas, en un intervalo de dos años, Francia e Inglaterra habían conseguido ocupar de forma casi permanente dos puntos diferentes del archipiélago ${ }^{15}$. En 1764 la compañía de Saint Malo había tomado posesión de las islas en nombre del rey de Francia, fundado el puerto de Saint Louis e implantado una colonia en la actual isla Soledad. Dos años después, los ingleses se establecieron en el puerto Egmont (o Port de la Croisade para los franceses), ubicado en un punto de la costa sureste de la isla Saunders perteneciente al archipiélago de Malvinas. Bougainville detalla la situación de los ingleses en las islas hacia el final del tercer capítulo de su Viaje alrededor del mundo, en donde se refiere al asentamiento en puerto Egmont de la siguiente forma:

... el comodoro Byron había venido en el mes de enero de 1765 a reconocer las islas Malvinas. Atracó al oeste de nuestro asentamiento, en un puerto que nosotros ya habíamos llamado puerto de la Cruzada [Port de la Croisade] y tomó posesión de estas islas para la Corona de Inglaterra, sin dejar allí ningún habitante. Fue recién en 1766 que los ingleses enviaron una colonia para establecerse en el puerto de la Cruzada, que llamaron puerto Egmont ${ }^{16}$.

Las noticias sobre los intentos de asentamiento franceses en las islas llegaron a oídos de las autoridades españolas en julio de $1764^{17}$. Poco después,

14 Zusman, 1999. Los principios papales eran los únicos en apoyar la defensa de las colonias americanas como posesión hispánica.

15 Groussac, 1936: 69.

16 Bougainville, 1771: 52-53. La traducción es nuestra. Véase también Groussac, 1936: 123.

17 «El 13 de julio de 1764, en su número 56, la Gaceta de Ámsterdam, dio a conocer la primera noticia pública, acerca de la expedición de Bougainville», Caillet-Bois, 1957: 10. 
recibirían informaciones acerca de la presencia de naves británicas en el Atlántico Sur. Frente al creciente poder de Gran Bretaña, potenciado por su victoria en la Guerra de los Siete Años, la importancia «geopolítica» que la Corona española otorgó a Malvinas se hizo evidente en las resoluciones que adoptara de forma casi inmediata ${ }^{18}$. Al tiempo que impulsó el pedido de restitución del archipiélago, re-articuló su accionar en América continental con el objetivo de impedir no sólo futuras incursiones francesas sino «cualquiera establecimiento que hayan intentado y hecho o que intenten y hagan los Yngleses en aquellos mares o costa» ${ }^{19}$. En principio, la creación de una subgobernación en Malvinas dependiente del gobierno de Buenos Aires se realizó en vista de integrar, al menos jurisdiccionalmente, ambos espacios ${ }^{20}$. En términos jurídicos, políticos y económicos el archipiélago pasó a depender entonces del Gobierno y la Capitanía General de Buenos Aires. A la vez, el temor a las eventuales incursiones continentales que los ingleses pudieran hacer desde el archipiélago intensificó el control de las costas insulares y patagónicas en las décadas siguientes. En 1766, a través del Marqués de Grimaldi, el rey ordenaba que dos fragatas reconocieran las costas americanas en busca de posibles merodeadores ingleses ${ }^{21}$. Si bien la amenaza inglesa se acentuaría con la firma del Tratado de París en 1763, la intención de preservar la Patagonia Oriental, el área magallánico-fueguina e islas circundantes de su posible ocupación por parte de Gran Bretaña encontraba sus antecedentes en las Reales Cédulas de noviembre de 1743 , y julio y diciembre de $1744^{22}$. Por

18 Barriera, 2019: 67. Sobre el surgimiento de Gran Bretaña como potencia a escala mundial y los orígenes del imperio británico moderno a partir de la pérdida de sus colonias norteamericanas en 1776 véase Bayly, 1989. En efecto, el interés de Gran Bretaña en Malvinas ocurrió en un período de crecimiento del imperio británico a escala global.

19 Caillet-Bois, 1957: 13.

${ }^{20}$ Caillet-Bois hace referencia a la «Real Orden al Gobernador de Buenos Aires, Francisco de Paula Bucareli, comunicándole que las islas Malvinas, a las que iba de gobernador el capitán de navío Felipe Ruiz Puente, quedaban dependientes de su gobierno y capitanía general; se le encarga que trate con dicho oficial de los auxilios que necesite y que le facilite un destacamento de veinte hombres naturales de la gobernación. 2 de octubre de 1766», Caillet-Bois, 1961: 32. Véase también Jiménez, Alioto y Villar, 2018: 27.

${ }^{21}$ Caillet-Bois, 1957: 157. Dentro de la selección de fuentes realizada por Caillet-Bois, se destaca la n. ${ }^{\circ}$ 34: "Oficio del Marqués de Grimaldi, a Julián de Arriaga, sobre la conveniencia de destinar dos fragatas al reconocimiento de los lugares en los que se suponía que los ingleses pretendían establecerse. 27 de marzo de 1766", de los Expedientes sobre el establecimiento de los ingleses en varios puntos, (años 1766-1770), Archivo General de Indias, Sevilla (AGI). Las directivas de Grimaldi al virrey Amat respecto del reconocimiento de establecimientos extranjeros en la zona del Estrecho de Magallanes e islas del Atlántico también son analizadas por Barriera, 2019: 61-62.

22 Caviglia, 2012: 87. 
su parte, los informes de contactos y avistamientos de navíos ingleses «entrando en mares y costas propios del dominio español» se volvieron una tarea frecuente por parte de las autoridades coloniales ${ }^{23}$. En 1791, por ejemplo, el virrey Nicolás Antonio de Arredondo notificó la partida de la «expedición de Malvinas», compuesta por el paquebote Santa Eulalia y el bergantín Rosario «destinados a practicar previamente los reconocimientos de las islas de los Estados y Nueva Irlanda en que por las noticias adquiridas se presumen los establecimientos de ingleses $\rangle^{24}$.

Asimismo, los mapas de las islas Malvinas producidos en este período evidencian el interés de la Corona española por acrecentar su conocimiento sobre las mismas y las aguas circundantes. En principio, España había obtenido sus primeras informaciones sobre las islas durante el proceso de restitución. Fue a partir del nombramiento de Felipe Ruiz Puente como gobernador, sin embargo, que se organizaron distintas expediciones con el objetivo de mapear las áreas de asentamiento inglesas y francesas y evaluar las condiciones geográficas que ofrecía el archipiélago. Si en 1766, a instancias del propio Bouganville, el embajador de Francia había entregado a España una memoria con sus observaciones sobre las islas ${ }^{25}$, las exploraciones de Felipe Ruiz Puente tras ser nombrado sub-gobernador buscaron completar las informaciones francesas obtenidas previamente.

La creación de una cartografía detallada de las posesiones españolas en ultramar debe interpretarse en el marco de un proceso de reformulaciones que la historiografía ha concebido tradicionalmente como reformas borbónicas, mediante las cuales la Corona española procuró reorganizar las distintas aristas del gobierno sobre sus dominios americanos hacia la segunda mitad del siglo XVIII. Dentro de sus múltiples objetivos, los borbones españoles aspiraron a mejorar el control de sus rutas comerciales oceánicas y evitar eventuales asentamientos ingleses en territorios nominalmente bajo dominio español pero escasamente poblados, para lo cual necesitaron conocer en profundidad la topografía de las áreas en juego ${ }^{26}$. En el caso de las islas Malvinas, el acopio y la capitalización de información francesa por parte de España se evidencia en la conservación en el Archivo General de Indias de una

${ }^{23}$ Marina inglesa, Madrid, 27 de diciembre de 1790, Archivo General de Simancas, Simancas, Valladolid (AGS), Secretaría de Estado y del Despacho de Guerra, leg. 6804, exp. 38 , folio $6 \mathrm{v}$.

${ }^{24}$ Malvinas. Colonias inglesas, 21 de enero de 1791, AGS, Secretaría de Estado y del Despacho de Guerra, leg. 6805, exp. 35, fol. 111-112.

${ }^{25}$ Caillet-Bois, 1957: 168. Martínez, 2017.

${ }^{26}$ Caviglia, 2012: 87. 
Carte d'une partie du Detroit de Magellan, et de l'île Malouine, dressée d'après les remarques du Sieur Thisbé de Bellecourt, Capitaine reformé d'infanterie, elaborada con fecha posterior a $1765^{27}$. Por otra parte, la reutilización de las tareas de relevamiento realizadas previamente por los franceses se observa en el «Plano de las Yslas Maluinas según se descubren desde las alturas de las Montañas A, B, C», confeccionado circa 1768. Más allá del título en español que el plano presenta en el margen superior derecho, la carta conserva en lengua francesa la toponimia y las leyendas explicativas que se encuentran en su margen izquierdo (figura 1).

\section{Figura 1. Plano de las YsLas Maluinas SeGÚN SE DESCUbren} DESDE LAS ALTURAS DE LAS MONTAÑAS A, B, C, 1768

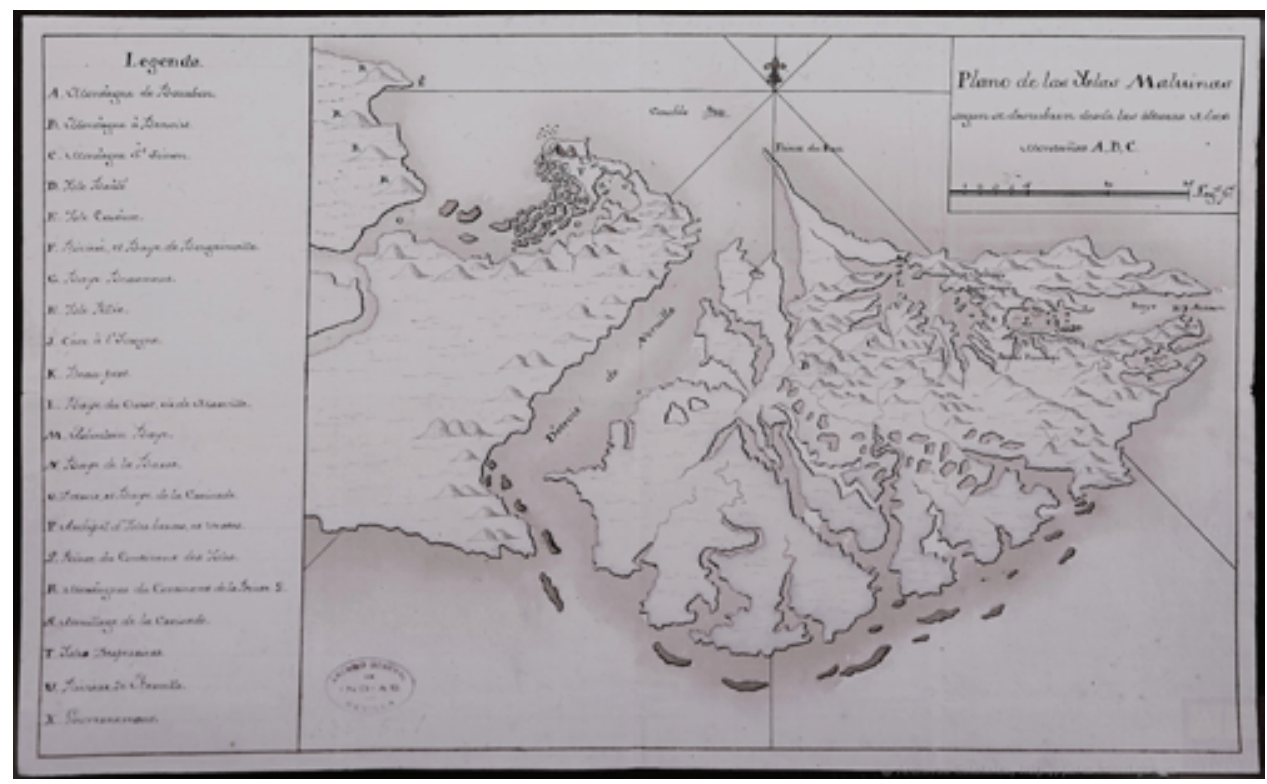

Fuente: Archivo General de Indias, Sevilla (AGI), Mapas, planos, documentos iconográficos y documentos especiales (MP), Buenos Aires, 73.

${ }^{27}$ Carte d'une partie du Detroit de Magellan, et de l'Île Malouine, dressée d'après les remarques du Sieur Thisbé de Bellecourt, Capitaine reformé d'infanterie, mapa anónimo con fecha posterior a 1765, AGI, Mapas, planos, documentos iconográficos y documentos especiales (MP), Buenos Aires, 67. 
Los avistamientos y mapas realizados por los franceses proveyeron a la Corona española las informaciones necesarias para fortalecer su presencia en el archipiélago de Malvinas, considerado un «escenario de conflicto» posible en un contexto mundial que a las claras resultaba favorable a Gran Bretaña ${ }^{28}$. En relación con este último punto, el intento de localizar cartográficamente los sitios en los que se hubiese detectado la presencia de los ingleses se observa en el plano de las islas confeccionado a partir de las incursiones de Ruiz Puente (figura 2) hacia 1769, período en el que España ya tenía conocimiento del asentamiento británico. En él, las letras $\langle\mathrm{T}\rangle,\langle\langle\mathrm{V}\rangle \mathrm{y}\langle\mathrm{S}\rangle$ marcan la «isla de la vigía de los ingleses», «la punta y entrada general del Puerto Egmont» y la «población de los ingleses» respectivamente. Esta modalidad se mantendrá e incluso acrecentará en los mapas sucesivos sobre el archipiélago. Así lo evidencian el «Plano y diseño de la población de Puerto Egmondt [sic], sacado el día 15 de noviembre de 1774» (figura 3) y el «Plano de perspectiva del Puerto de Egmondt [sic] levantado en 24 de enero de 1776, por el piloto del número de la Real Armada, y capitán del bergantín San Francisco de Paula; hallándose este puerto abandonado por los ingleses, en la disposición que se demuestra $\rangle^{29}$. El temor a una posible reocupación por parte de Gran Bretaña se manifiesta en el hecho de que estos documentos fuesen confeccionados en 1774 y 1776, coincidiendo con el abandono del Puerto de Egmont y con la recuperación del mismo por los ingleses ${ }^{30}$. En efecto, el título del segundo plano mencionado hace especial énfasis en que el puerto se encontraba abandonado en el momento en que la Corona española realizó el relevamiento ${ }^{31}$.

28 Barriera, 2019: 58.

29 Plano de perspectiva del Puerto de Egmondt [sic] levantado en 24 de enero de 1776, por el piloto del número de la Real Armada, y capitán del bergantín San Francisco de Paula; hallándose este puerto abandonado por los ingleses, en la disposición que se demuestra, 26 de enero, AGI, MP, Buenos Aires, 112.

${ }^{30}$ La corona española localizó puerto Egmont por primera vez en 1770. A partir de este hallazgo, producido por la expedición comandada por Fernando de Rubalcava, se enviaron desde Montevideo cuatro fragatas cuyo objetivo era la expulsión de los ingleses. Si bien el puerto fue entregado sin resistencia, la intervención española fue reprobada por el gobierno inglés al enterarse de lo sucedido en las islas. Las tensiones en ciernes fueron sosegadas por Luis XV quien, en vista de los posibles costes de un conflicto armado con Gran Bretaña y las obligaciones de Francia para con la casa Borbón (española) a raíz del tercer Pacto de Familia, convenció a Carlos III de minimizar lo sucedido en Malvinas frente a Gran Bretaña. En 1771 puerto Egmont fue restituido a Inglaterra por parte de España. Jiménez, Alioto y Villar, 2018: 31. Caviglia, 2012: 116.

31 En mayo de 1774 los ingleses abandonaron definitivamente el puerto fundado por Byron, alejándose del archipiélago hasta su regreso en 1776. Jiménez, Alioto y Villar, 2018: 32. 
Figura 2. Plano de las Yslas Maluinas situadas en la LATITUd de 51 GRADOS 28 MINUTOS SUR Y EN 316 GRADOS 30 MINUTOS DE LONGITUD SEGÚN EL MERIDIANO DE TENERIFE ARREGLADO A LOS ÚLTIMOS RECONOCIMIENTOS HECHOS EN ELLAS POR Mar y Tierra de Orden de su Governador D. Phelipe Ruiz Puente

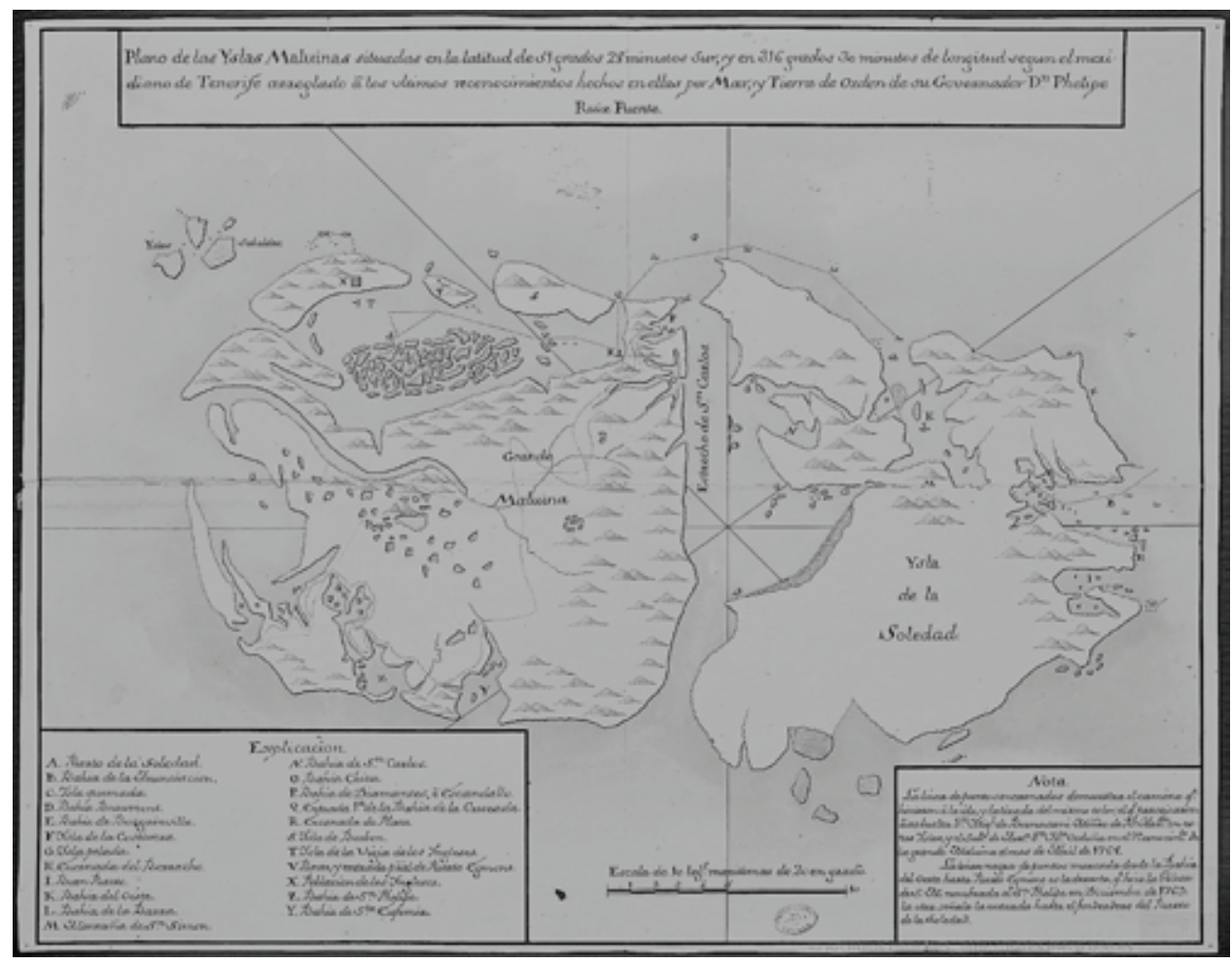

Fuente: AGI, MP, Buenos Aires, 82.

Sin duda, en las tareas de reconocimiento del archipiélago y su articulación con el espacio colonial americano jugaron un papel de primer orden las autoridades locales ${ }^{32}$. A sus atribuciones políticas se sumaron sus competencias en temas prácticos, tales como la provisión de armas, municiones y vituallas necesarias para la consolidación de un establecimiento permanente en las islas. En los hechos, esta estrategia imperial fue articulada local y regionalmente por

${ }^{32}$ La posición adoptada por las autoridades virreinales en el marco de los intereses y acciones desarrolladas por las autoridades locales, la corona y el virreinato del Perú ha sido examinada en detalle por Barriera, 2019: 62-63. 
actores porteños, que encontraron un negocio redituable en la financiación de la empresa de Malvinas anticipando los capitales necesarios para su desenvolvimiento y garantizando sus retornos con los fondos de la Real Hacienda.

Figura 3. Plano y diseño de la población de Puerto Egmondt [Sic], SACADO EL DÍA 15 DE NOVIEMBRE DE 1774

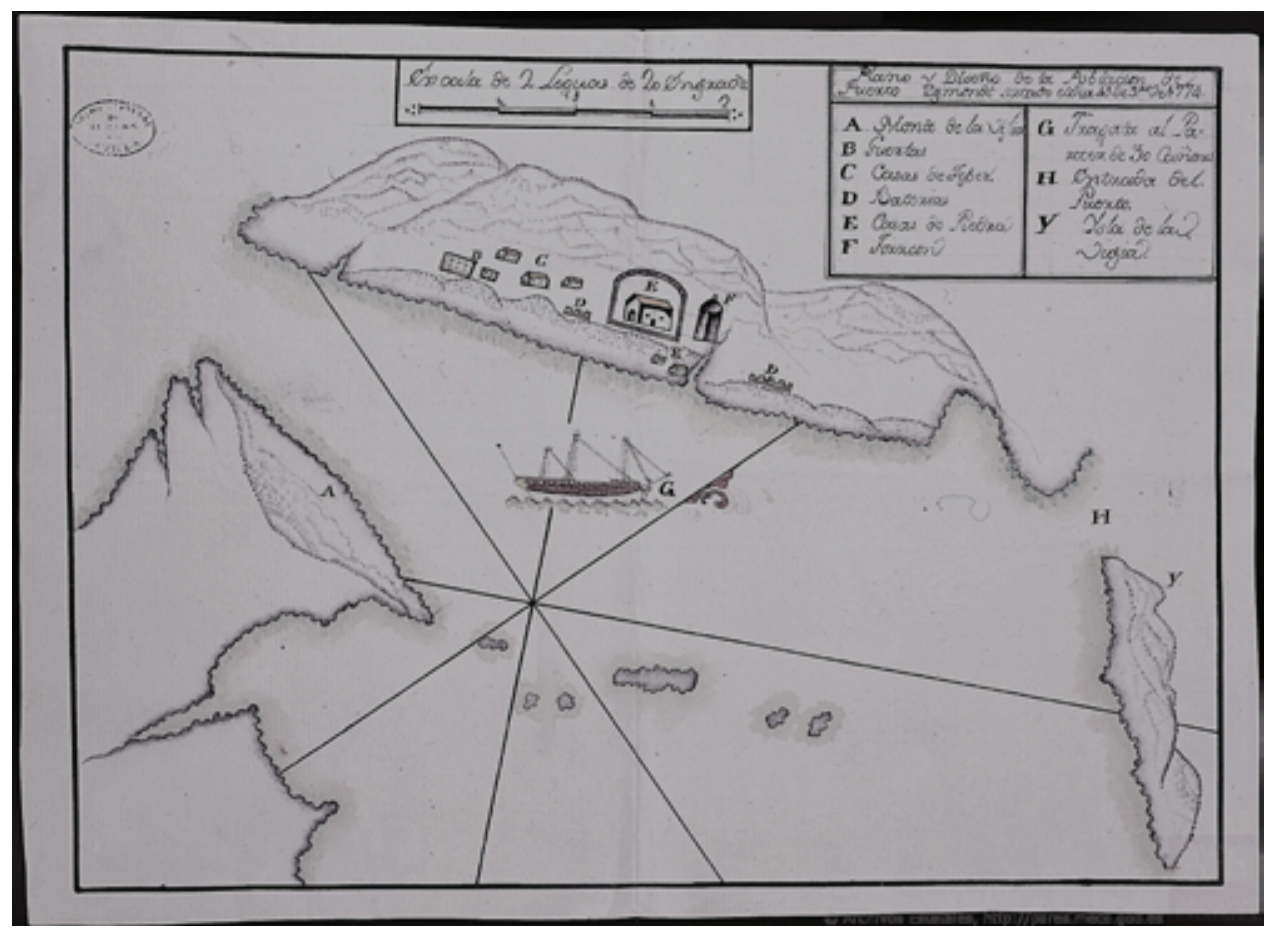

Fuente: 15 de noviembre de 1774, AGI, MP, Buenos Aires, 103.

III. Recursos locales para un objetivo imperial: el Real Situado y el CRÉDITO RIOPLATENSE EN LA COLONIZACIÓN DE LAS ISLAS MALVINAS

La financiación local de esta empresa imperial se apoyaba, primordialmente, en el Real Situado, un sistema mediante el cual las jurisdicciones con elevada recaudación local enviaban recursos excedentes a las cajas de Real Hacienda ubicadas en bastiones claves para la defensa imperial en América ${ }^{33}$. En relación

${ }^{33}$ Marichal y Grafenstein, 2012: 15 y ss. 
con el Río de la Plata, las cajas de Potosí eran las principales proveedoras de este subsidio a la real caja de Buenos Aires, cuya ubicación estratégica resultaba condicionante para resguardar la integridad imperial ante amenazas externas, pero también para coordinar empresas expansivas en coordinación con Montevideo ${ }^{34}$.

En efecto, el Situado de Buenos Aires ocupó un lugar protagónico en los ingresos de la tesorería porteña, promediando el $70 \%$ de los mismos desde 1767 y hasta $1774^{35}$. Y dichos recursos resultaban centrales tanto para defender al complejo del Río de la Plata, como para asegurar la integridad de su jurisdicción cambiante. En este sentido, parte de los recursos llegados con el Situado a la ciudad eran aplicados por los oficiales reales porteños a otras regiones y localidades alcanzadas por la jurisdicción bonaerense ${ }^{36}$. La redistribución regional de los fondos del situado de Buenos Aires puede visibilizarse analizando la administración contable de los mismos (gráfica I).

\section{GrÁfica 1: DistRIBUCIÓN REGIONAL DE FONDOS DEL REAL SitUADO DE BUENOS AIRES, 1767-1774}

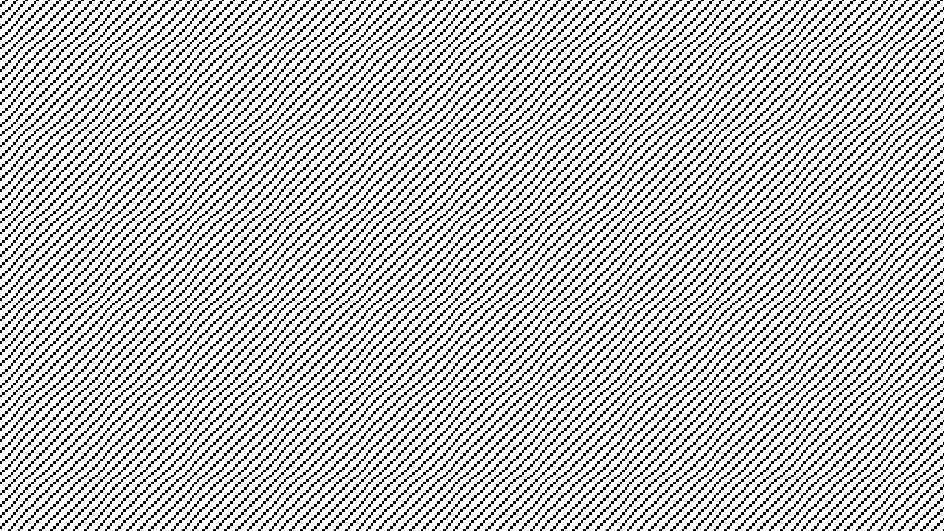

Fuente: Elaboración propia en base a Libros Principales de Cargo y Data del Ramo de Situados de la Real Caja de Buenos Aires, 1767-1774, Archivo General de la Nación, Buenos Aires (AGN), XIII, 42-1-20, 42-1-21, 42-1-22, 42-1-23, 42-1-24, 42-1-25.

${ }^{34}$ Véase Gelman, 2012. Sobre la articulación entre Montevideo y Malvinas, véase Groussac, 1936: 117-143. Destefani, 1970: 12. Rees Jones, 1992: 203.

${ }^{35}$ Wasserman, 2017.

36 En este sentido, Martín Cuesta, 2009: 132 y ss., en línea con Tulio Halperín Donghi, propone que entre 1791 y 1795 la caja de Buenos Aires sólo desembolsó localmente el $28 \%$ de sus erogaciones totales. El $39 \%$ se habría destinado a la consolidación de las distintas fronteras (Paraguay, Patagonia, islas Malvinas) y el 33 \% remitido a la Península. 
De esta manera, más del $65 \%$ de los fondos eran retenidos en Buenos Aires, destinados primordialmente a cubrir el prest - haberes - de la guarnición del presidio local ${ }^{37}$. El $45 \%$ de los fondos restante era por lo tanto redistribuido hacia diversos puntos. El conflictivo frente portugués queda expresado en las sumas destinadas a la banda oriental del Río de la Plata ${ }^{38}$ y diversas localidades del Brasil ${ }^{39}$. Entre tanto, la expulsión de la Compañía de Jesús absorbió un 2,5\% de aquellos fondos, reexpedidos a la zona de las misiones.

Pero más del $11 \%$ de los fondos del situado bonaerense se aplicó a sostener los gastos generados por los viajes, expediciones y consolidación del establecimiento hispánico en las islas Malvinas. Y si se atiende al hecho de que buena parte de la organización de las expediciones al archipiélago pasaba por (y zarpaba de) Montevideo, entonces al menos una porción de los fondos que se destinaban a las localidades orientales fue aplicado también a cubrir la empresa de las islas Malvinas ${ }^{40}$. Es así como los 707.764,46 \$ destinados taxativamente a islas Malvinas por el conducto del Situado de Buenos Aires, constituyen sólo la parte contablemente explicitada de los recursos aplicados por la Hacienda Real a la colonización del archipiélago.

Tal como puede observarse en la gráfica II, más del $61 \%$ de los recursos del Situado que eran destinados expresamente a islas Malvinas (436.434,82 \$) se aplicaban al reintegro de créditos y avíos que una multiplicidad de acreedores y proveedores ofrecieron para abastecer de víveres, habilitar embarcaciones, garantizar materiales para la erección y mantenimiento de establecimientos, vestir a la tropa y proveer a las islas de medicamentos, armamentos, pólvora y municiones ${ }^{41}$.

37 Véase Wasserman, 2018.

38 En la cual quedan agrupadas las localidades de Santo Domingo Soriano, Colonia del Sacramento, Montevideo, Maldonado y San Carlos.

39 Primordialmente, Santa Teresa, Río de Janeiro, Río Grande y Santa Tecla.

${ }^{40}$ Asimismo, una porción de las erogaciones efectuadas en el distrito de Buenos Aires era recibida por sujetos itinerantes que conducían esos fondos a otras plazas, como Montevideo.

${ }^{41}$ En principio, desde la restitución del archipiélago, el gobierno de Buenos Aires había tenido por objetivo sustituir las fuerzas militares que los franceses habían establecido en el fuerte construido por Bougainville en la isla Soledad. Es probable que las "Reflexiones sobre los medios para comenzar el establecimiento de las islas Malvinas", realizadas por Bougainville a raíz de la ocupación del archipiélago y entregadas al Marqués de Grimaldi en el contexto de la restitución, proveyeran información precisa acerca de los recursos necesarios para la implantación de una colonia en las islas. La transcripción completa del documento puede ser consultada en Caillet-Bois, 1957: 172-176. 


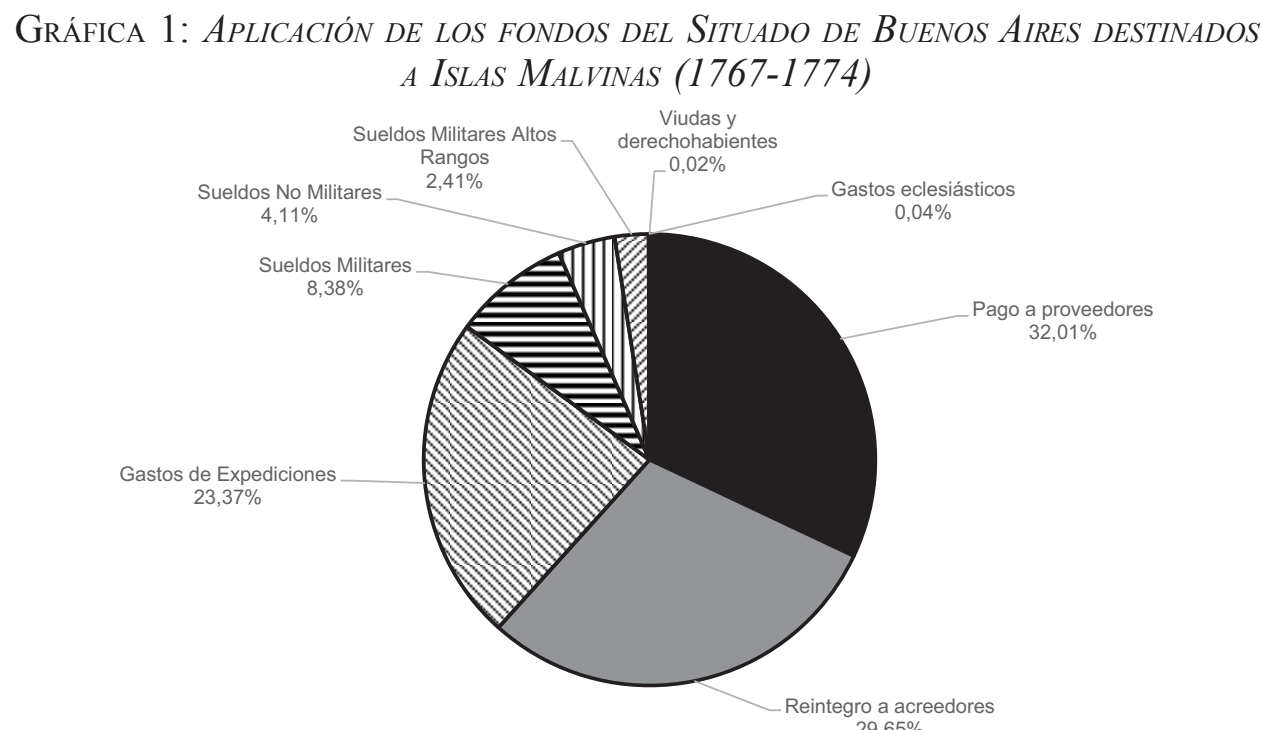

Fuente: Elaboración propia en base a Libros Principales de Cargo y Data del Ramo de Situados de la Real Caja de Buenos Aires, 1767-1774, Archivo General de la Nación, Buenos Aires (AGN), XIII, 42-1-20, 42-1-21, 42-1-22, 42-1-23, 42-1-24, 42-1-25.

TABla I: ReINTEgRos A ACREEDORES Y PAGOS A PROVEEDORES Situado de Buenos Aires APlicado a islas Malvinas, 1767-1774

\begin{tabular}{|l|c|c|}
\hline Motivo de reintegro & Suma & \% \\
\hline Mantenimiento y habilitación de embarcaciones & 149953,281 & $34,4 \%$ \\
\hline Suplementos monetarios & 142551,625 & $32,7 \%$ \\
\hline Víveres & 89313,8281 & $20,5 \%$ \\
\hline Mantenimiento y habilitación de establecimientos & 41644,7075 & $9,5 \%$ \\
\hline Vestimenta & 10231,8438 & $2,3 \%$ \\
\hline Medicamentos & 1973,84375 & $0,5 \%$ \\
\hline Armamento y pólvora & 765,6875 & $0,2 \%$ \\
\hline Total general & 436434,817 & $100 \%$ \\
\hline
\end{tabular}

Fuente: Elaboración propia en base a Libros Principales de Cargo y Data del Ramo de Situados de la Real Caja de Buenos Aires, 1767-1774, Archivo General de la Nación, Buenos Aires (AGN), XIII, 42-1-20, 42-1-21, 42-1-22, 42-1-23, 42-1-24, 42-1-25.

El $30 \%$ de aquellos reintegros por créditos y anticipos entregados para la empresa de islas Malvinas tuvo por destinatarios a «individuos del comercio» de Buenos Aires, que habilitaron numerario colectivamente en dos oportunida- 
des entre 1767 y 1774: así, «cinco individuos de este comercio» no individualizados en el libro contable, habían suministrado los días 16 y 17 de febrero de 1767 la cuantiosa suma de 75.000 \$ para «la expedicion a las islas Malvinas y descubrimiento de la Tierra del Fuego». El monto les era reintegrado menos de un mes después, el 12 de marzo del mismo año, en plata doble ${ }^{42}$. Durante la primavera de 1767 , los días 25 de septiembre, 20 de octubre y 14 de noviembre, un colectivo de «40 individuos de este comercio» aportaron la sideral suma de $105.688,25$ \$ «para las urgencias del Real Servicio», contribuyendo a la habilitación de la fragata Venus en efectivo; la mitad del monto les era reintegrada el $1^{\circ}$ de marzo de 1768 con plata doble procedente del Real Situado, momento en que Altolaguirre, Bustinaga y Valle (oficiales reales de la Caja de Buenos Aires), dejaban asentado que «la mitad restante se les satisfara luego que aya caudales para ello» ${ }^{43}$. Estos destellos documentales constatan que las dilaciones temporales que caracterizaron al mecanismo del Situado volvían imprescindible el recurso al crédito de los comerciantes locales para movilizar fondos que, de otro modo, habrían de llegar con una demora crítica.

Financiar a la Real Hacienda era, para los grandes comerciantes de Buenos Aires, una inversión cuyos réditos deben buscarse no sólo en los reintegros en moneda doble, sino también en la obtención de una mejor correlación de fuerzas para negociar con la Corona sus propios intereses ${ }^{44}$. El condicionamiento financiero que los comerciantes locales imponían a la Corona para el despliegue regional de la estrategia imperial, sería capitalizado por el colec-

${ }^{42}$ Caja de Buenos Aires. Situados. Principal de Cargo y Data (1766-1768), 12 de marzo de 1767, AGN, XIII, 42-1-20, f. 75r. Los reintegros en plata doble representaban un negocio en sí mismo, en función de los premios arrojados por las piezas de alta denominación sobre las de baja denominación. Véase Gelman, 1987 y Wasserman, 2017.

${ }^{43}$ Caja de Buenos Aires. Situados. Principal de Cargo y Data (1766-1768), 1 de marzo de 1768, AGN, XIII, 42-1-20, f. 99r.

${ }^{44}$ La historiografía relativa al enlace entre gasto militar y financiación local en el contexto monárquico es profusa y la centralidad de este eje investigativo implica una creciente producción reciente. La participación de grupos dominantes locales en el campo fiscal se replica a escala imperial, tal como lo ponen en evidencia los trabajos recuperados por Solbes, Dubet, Bertrand y Torres Sánchez, 2015 y, más recientemente, por 'T Hart, Pepijn y Torres Sánchez, 2018. Allí puede constatarse que en distintas latitudes de la Monarquía, grupos de intereses privados incidían en la administración de la Hacienda, de manera directa o indirecta, mediante contratos, asientos u otras modalidades expuestas a distintos grados de discrecionalidad y condicionamientos relacionales. En esa historiografía es posible comprender que la participación de esos actores era requerida no sólo para la recaudación sino, como se postula aquí, para la ejecución del gasto militar, principal renglón de gastos en la Hacienda imperial, como lo ha demostrado a su vez la paradigmática historiografía sobre el gobierno fiscal-militar. Véanse, entre otros, lo siguientes: Brewer, 1989. Pincus y Robinson, 2016. Torres Sánchez, 2013b. González Enciso, 2008. Del Valle Pavón, 2011. Solbes, 2015. Wasserman, 2018. 
tivo de comerciantes cuando se instituyesen corporativamente en 1779 como Junta de Comercio, luego transformada hacia 1794 en Consulado de Comercio de Buenos Aires ${ }^{45}$. La sedimentación de sucesivos empréstitos para socorrer al crónico déficit fiscal de la Hacienda Real ${ }^{46}$ y para concretar las empresas monárquicas de avance sobre el Atlántico Sur, redituaba para los comerciantes porteños en una herramienta institucional con la cual mejorar la negociación de sus propios intereses ${ }^{47}$. La importancia defensiva de la expedición y establecimiento de las islas Malvinas ofrecía así un punto de confluencia entre los intereses de los «individuos del comercio» de Buenos Aires y la Corona, toda vez que las ganancias de los primeros resultaban de garantizar y volver inmediatamente operativa la defensa de la soberanía monárquica, en un territorio en el cual el archipiélago de Malvinas y la región patagónica ocupaban un lugar capital en vista de los avances ingleses ${ }^{48}$.

Junto con los «individuos del comercio» de Buenos Aires, el financiamiento porteño de la colonización española en las islas Malvinas fue protagonizado por otros tres sujetos que concentraron el $50 \%$ del crédito a la Hacienda para esta empresa: se trata de los asentistas de víveres Francisco de Llano San Ginés, Juan Ignacio de Elia y Martín de Sarratea ${ }^{49}$.

Francisco de Llano San Ginés fue un próspero naviero, cuyos negocios con la Real Hacienda habían dado sus primeros pasos durante el gobierno de Cevallos (1756-1766), participando con la provisión de materiales para la reforma del fuerte de Buenos Aires. Sus negocios con la Hacienda se intensificaron con ocasión del extrañamiento de los jesuitas, oportunidad en la que habilitaría la infraestructura necesaria para el procedimiento ${ }^{50}$. El lazo entre San Ginés y el gobernador Bucarelli (1766-1770) — quienes regresarían juntos a España - queda evidenciado en la denuncia que Cevallos haría tiempo después contra Bucarelli, acusándolo de una asociación ilegal que le habría provisto réditos por $500.000 \$$ a San Ginés ${ }^{51}$. La mera acusación permite comprender que el enlace entre Bucarelli y San Ginés pudo habilitarle a éste

${ }^{45}$ Kraselsky, 2011.

46 Sobre el déficit crónico de la Hacienda Real española, véase Torres Sánchez, 2015.

${ }^{47}$ Irigoin y Grafe, 2008. Valle Pavón, 2016. Kraselsky, 2011. Grieco, 2019.

${ }^{48}$ Ha sido señalado ya cómo en las décadas posteriores a la firma del Tratado de París (1763) el reconocimiento y apropiación de la Patagonia se volvieron un objetivo central de la monarquía española, que temía el avance británico sobre territorios nominalmente bajo su jurisprudencia.

49 Sobre la condicionante capacidad crediticia del asentista véase Torres Sánchez, 2013a: 176. Sandrín, 2014: 97.

${ }^{50}$ Herrero Gil, 2013.

${ }^{51}$ Idem. Sobre la red implicada en la confrontación entre Cevallos y Bucarelli, véase Moutoukias, 1992. 
el acceso al asiento de víveres, y la participación de San Ginés en el financiamiento de la empresa de Malvinas podría comprenderse por lo tanto como expresión de aquellos lazos que arrojaban beneficios mutuos.

San Ginés, quien captaría el 15,57 \% de los reintegros erogados por el Situado aplicado a Malvinas, recibía ya en octubre de 1767 la importante suma de 10.000 \$ por el anticipo que había realizado de víveres y «otros efectos a las islas Malvinas, para la subsistencia de la tropa y demas gente que las guarnece $»^{52}$. En 1768 el gobierno volvía a recurrir a este asentista: el 5 de enero de 1769 se le reintegraba la suma de 8.275,5 \$ que había provisto en víveres para Malvinas ${ }^{53}$ y dos días después se le pagaban otros $28.829,12 \$$ por «los viveres y utensilios» que había suplido «a los dos vergantines de SM nombrados San Francisco de Paula y San Raphael, destinados al descubrimiento de la Tierra del Fuego y su establecimiento, para dos viajes, sueldos y gratificaciones de oficiales, que los mandaron, gastos de sus carenas y [sostenimiento] de quatro religiosos $\gg{ }^{54}$. Ese mismo mes, San Ginés embolsaba otros $10.700,18$ \$ como reintegro a los víveres «que ha subministrado para subsistencia en este puerto de la fragata del Rey nombrada Santa Rosa, hasta su salida al viaje de las islas Malvinas $\rangle^{55}$. Y todavía en mayo de 1770 seguía recibiendo elevados montos del ramo de Situados, como los $10.133,78$ \$ por el «bestuario que en virtud de comision del excelentisimo señor governador ha mandado hacer para la gente que va a la expedicion y entregó al presente ministro de Marina para distribuir entre la misma gente ${ }^{56}$.

A partir de 1770 el pamplonés Juan Ignacio de Elía pasaría a protagonizar el escalón de los acreedores del Situado para Malvinas, y captaría el 17,80 \% de los reintegros pagados por el Situado aplicado al archipiélago. Su enlace con María Bárbara García de Zúñiga lo hizo cuñado de Juan Francisco García de Zúñiga, propietario de tierras en ambas bandas del río Uruguay, así como concuñado de los coroneles Warnes y Calceite, consolidando su inserción en una red con poder militar y territorial: lazos con un segmento oligárquico local que aceitaron su participación en los negocios con la Real Hacienda ${ }^{57}$. Así, en marzo de aquel año los oficiales de la Real Caja de Buenos Aires reintegraban a Elía la considerable suma de $11.483,12$ \$ por su «provisión de

52 Caja de Buenos Aires. Situados. Principal de Cargo y Data (1766-1768), Buenos Aires, 29 de octubre de 1767, AGN, XIII, 42-1-20, f. 88v.

53 Libro Principal de Situados (1769-1772), Buenos Aires, 5 de enero de 1769, AGN, XIII, 42-1-21, f. 40v.

${ }_{54}$ Ibidem, 7 de enero de 1769, AGN, XIII, 42-1-21, f. 40v.

55 Ibidem, 10 de enero de 1769, AGN, XIII, 42-1-21, f. 41r.

${ }^{56}$ Ibidem, 23 de mayo de 1770, AGN, XIII, 42-1-21, f. 66v.

57 Véase Pardo de Guevara y Valdés, 2015: 835. Mayo, 1987. Saguier, 2004-2007. 
útiles para la fragata real Santa Catalina con destino islas Malvinas $\rangle^{58}$, y a fin de ese mes le liquidaban otros 27.000 \$ «para abilitar de los necesarios y demas utiles a las fragatas del Rey Santa Cathalina, Industria, Santa Barbara, Chambequin y Santa Rosa, para su viaxe a Malvinas al desalojo de los Yngleses ${ }^{59}$. Ya se ha señalado cómo, desde la restitución del archipiélago, este tipo de incursiones se volvió una actividad frecuente a cargo de las autoridades locales, que asumieron la función de vigilar las aguas del Atlántico austral frente a posibles incursiones inglesas; la referencia al «desalojo de los Yngleses» remite específicamente a la expulsión de la guarnición inglesa de Puerto Egmont en 1770. La escuadra, encabezada por la fragata Santa Catalina, fue enviada por Francisco de Paula Bucarelli en los últimos meses de su gobierno y tuvo por objetivo hacer cumplir la ordenanza real de 1768, que había establecido la expulsión de cualquier asentamiento británico en el archipiélago ${ }^{60}$.

Como se ve, el financiamiento de actores como Elía para la habilitación de este tipo de embarcaciones resultaba condicionante en un punto crítico del proceso: en abril le eran pagados 10.300 \$ que había anticipado «para continuar la avilitacion de ellos y demas utiles a las fragatas del Rey que pasan a Malvinas» ${ }^{61}$, recuperando en 1771 otros 4.422,70 \$ que suplió en efectos «al Ministro de Marina don Patricio del Villar, para su remision a las islas Malvinas en reemplazo de los que dexaron los ingleses en el Puerto Egmon» ${ }^{62}$. Así, Elía financiaba la disputa española del archipiélago a Gran Bretaña, y continuaba aportando 5.725,25 \$ para «la carena y avilitazion del bergantin San Francisco de Paula del mando del theniente de fragata don Manuel Pardo para su viaje a las islas Malvinas» ${ }^{63}$, enviando a Malvinas «carretadas de leña» por 313,25 $\$^{64}$, o

58 Libro Principal de Situados (1769-1772), Buenos Aires, 23 de marzo de 1770, AGN, XIII, 42-1-21, f. 69v.

59 Ibidem, 31 de marzo de 1770, AGN, XIII, 42-1-21, f. 60v.

${ }^{60}$ «Hacia el mismo tiempo, el gobernador de Buenos Aires había dado orden al jefe de la división naval de Montevideo, don Juan Ignacio Madariaga, de enviar a las Malvinas la fragata Santa Catalina con dos embarcaciones de pequeño tonelaje para registrar la costa. La expedición fue confiada al capitán de fragata don Fernando Rubalcaba quien, llegado a Puerto Soledad hacia fines de enero de 1770, emprendió algunos días después la exploración de la costa norte, de este a oeste, y el 19 de febrero "descubrió", al fin, el puerto de la Croisade (Egmont), donde se hallaba anclada la fragata Tamar, mandada por Antonio Hunt», Groussac, 1936: 127.

${ }^{61}$ Libro Principal de Situados (1769-1772), Buenos Aires, 24 de abril de 1770, AGN, XIII, 42-1-21, f. 63v.

${ }^{62}$ Ibidem, 18 de octubre de 1771, AGN, XIII, 42-1-21, f. 103r.

${ }^{63}$ Ibidem, 19 de octubre de 1881, AGN, XIII, 42-1-21, f. 103v.

${ }^{64}$ Ibidem, 6 de noviembre de 1771, AGN, XIII, 42-1-21, f. 104v. 
«ganados, cal, ladrillo y demas efectos» que por importe de 13.591,25 \$ había remitido «a Montevideo para su conduzion a las islas Malvinas en el navio La Concepcion, y subvenir a la subsistencia de aquellos establecimientos ${ }^{65}$. Elía volvería a enviar este tipo de materiales y útiles por importe de $2.849,90 \$$ «a Montevideo para embarcar en la fragata del rey nombrada Santa Barbara» con destino «a las islas Malvinas, para las urgencias que ocurran en aquellos establecimientos $\rangle^{66}$.

Desde 1772, el proceso de avance español sobre el archipiélago continuaría financiado localmente por Martín de Sarratea, quien lograba posicionarse como asentista de víveres, protagonizando desde entonces el financiamiento de la empresa imperial en Malvinas y recibiendo el 18,58 \% de los reintegros pagados por el Situado aplicado a la colonización del archipiélago. Sarratea había nacido en Guipúzcoa, y en Buenos Aires logró participar de una red que contaba entre sus nodos más sobresalientes a los oficiales reales de la Hacienda local y al propio gobernador don Pedro de Cevallos. En efecto, el factor Martín de Altolaguirre, suegro de Sarratea tras el casamiento de éste con Tomasa de Altolaguirre, le encomendaría a éste la administración del capital crediticio que los Altolaguirre no podían gestionar directamente ${ }^{67}$.

Su participación en el financiamiento de Malvinas comienza a constatarse cuando, entre abril y mayo de 1772, la Real Caja de Buenos Aires le reintegrase la considerable suma de $81.104,36 \$$ en cuatro partidas que indican que sus créditos y anticipos se focalizaban ya no en la avanzada sobre el archipiélago sino en la consolidación del asentamiento español en Malvinas. Así, el 25 de abril de 1772 se le liquidaban 1.844,37 \$ por el «vino, ganado y otros efectos remitidos por la fragata de guerra La Industria a las islas Malvinas ${ }^{68}$. Pero también financiaría la regularización de la conexión entre Malvinas, Río de la Plata y España: el 8 de mayo de 1772 se le pagaban 34.017 \$ «a buena quenta del importe de los que ha subministrado al navio de guerra nombrado San Julian y demas embarcaciones de SM que regresan a España con las tropas y las destinadas a las islas Malvinas ${ }^{69}$, y a fin de ese mes se le reconocían $30.000 \$$ que había anticipado «para la mas prompta avilitazion de los bageles que retornan con tropas a España y de las dos fragatas que deven pasar a Malvinas» ${ }^{70}$. En

\footnotetext{
${ }^{65}$ Ibidem, 22 de enero de 1772, AGN XIII, 42-1-21, f. 109r.

${ }^{66}$ Ibidem, 24 de febrero de 1772, AGN, XIII, 42-1-21, f. 111v.

${ }^{67}$ Moutoukias, 1992. Como es de suponer, Sarratea lograría acceder al asiento de víveres una vez retirado Bucarelli del escenario rioplatense.

${ }^{68}$ Libro Principal de Situados (1769-1772), Buenos Aires, 25 de abril de 1772, AGN, XIII, 42-1-21, f. 114v.

${ }^{69}$ Ibidem, 8 de mayo de 1772, AGN, XIII, 42-1-21, f. 115v.

${ }^{70}$ Ibidem, 27 de mayo de 1772, AGN, XIII, 42-1-21, f. 116r.
} 
septiembre de 1772, en suma, se le pagaban otros 15.243 \$ por la provisión de víveres, incluyendo «el importe de los subministros a los bageles del Rey que regresaron a España y verificaron su viage a Malvinas $»^{71}$.

Entre los acreedores de la Hacienda también figuran algunos procedentes desde el seno mismo de la Real Caja porteña. En 1773, Martín Joseph de Altolaguirre, factor de Real Hacienda en Buenos Aires (e hijo de Martín de Altolaguirre), aportaba 1.681 \$ en víveres para conducir a «las islas Malvinas en la fragata de guerra Nuestra Señora del Carmen, para la subsistencia de la tropa destacada en aquel establecimiento ${ }^{72}$, y en octubre de 1774 se le reintegraba la considerable suma de 11.957,63 \$ «por importe de viberes, cal, madera, generos de marina y otros varios menesteres» que fueron remitidos en 1773 «a las islas Malvinas, en el primero y segundo viage que hizo el bergantin el Santo Christo del Buen Fin, y en la fragata de guerra La Asumpcion» ${ }^{73}$. No sorprende que el mismísimo factor de la Real Caja interviniese como financista de la Hacienda si comprendemos que el asentista Martín de Sarratea era su cuñado y administraba el crédito de la familia Altolaguirre.

Se constata hasta aquí que el destino del financiamiento provisto por comerciantes y asentistas de Buenos Aires se amoldaba con dinamismo a los cambios que experimentaba la política imperial en vista de consolidar sus posiciones en el Atlántico Sur: se advierte la financiación de una primera fase destinada al reconocimiento del terreno y al control de potenciales incursiones extranjeras en territorios bajo posesión de la Corona española, así como la financiación de una segunda fase destinada al asentamiento permanente y a consolidación de la población estable en el archipiélago de Malvinas. Tanto una fase como la otra estuvieron condicionadas por la capacidad crediticia de la oligarquía rioplatense y los réditos potenciales que encontraba en dicha empresa.

Como puede observarse, el avance español sobre islas Malvinas y la consolidación del asentamiento rioplatense en el archipiélago se vieron dinamizados por la capacidad crediticia de negociantes porteños que, con su financiamiento, podían contrarrestar las dilaciones del Situado y garantizar la provisión de recursos con la presteza que requería la estrategia militar; en otros términos, su crédito era condicionante para adecuar los plazos fiscales a las urgencias defensivas, a la vez que constituía un campo de negocios redituables para este estrecho grupo de actores. La capacidad que la Hacienda Real tenía para volver efectiva la ocupación de islas Malvinas y tornar ope-

71 Ibidem, 26 de septiembre de 1772, AGN, XIII, 42-1-21, f. 122v.

72 Ibidem, 7 de diciembre de 1773, AGN, XIII, 42-1-22, f. 50v.

73 1774-1775. Caja de Buenos Aires. Situados. Principal de Cargo y Data, 18 de octubre de 1774, AGN, XIII, 42-1-23, f. 102r. 
rativa la colonización española del archipiélago dependía, por lo tanto, de la capacidad financiera de estos acreedores y de los réditos lucrativos que su intervención les arrojase.

A su vez, el potencial capitalizado por los acreedores bonaerenses, financistas de primera instancia de la presencia española en Malvinas, retroalimentaba las tensiones con el Tribunal de Cuentas de Lima y con el virrey del Perú. Los acreedores, asentistas de víveres y proveedores de Buenos Aires pugnaban por la regularización del Situado y el aumento de sus envíos, toda vez que ello garantizaba un retorno favorable a su crédito (consistente ni más ni menos que en reintegros en moneda doble, cuyo diferencial harían valer en el mercado cambiario local). Ello se traducía en los reclamos que los oficiales reales de Hacienda de Buenos Aires y su gobernador elevaban al virrey Amat con creciente insistencia desde 1769: conminaban al virrey del Perú a ejecutar un aumento del Situado y regularizar su frecuencia. Buscando apoyo a sus demandas en Julián de Arriaga, los oficiales reales y el gobernador de Buenos Aires intentaban revertir la posición limeña, enunciada por el virrey pero sostenida en los argumentos del Tribunal de Cuentas de Lima, según la cual Buenos Aires debía incrementar su ahorro fiscal en lugar de solicitar situa$\operatorname{dos}^{74}$. Es que liberar los situados retenidos por la administración limeña no sólo implicaba desviar fondos fiscales hacia latitudes comercialmente inconvenientes para la plaza peruana; también implicaba potenciar la gravitación de los actores protagónicos de esa economía porteña.

La consolidación de la presencia española en el archipiélago de Malvinas dependió por lo tanto de financistas locales, cuyo apoyo a la empresa imperial se tradujo en réditos monetarios, reconocimiento institucional y el fortalecimiento de redes relacionales empleadas a escala local. Su capacidad financiera no sólo permitía articular materialmente la estrategia imperial en la escala regional, sino que retroalimentaba la capacidad de negociación de estos actores locales con una Corona que, pocos años después, haría de Buenos Aires la cabecera de un nuevo Virreinato, con su propio Tribunal Mayor de Cuentas en materia hacendaria y un Consulado que privilegiaría a sus comerciantes. Los intereses defensivos de la Corona se conciliaban de este modo con los intereses de una oligarquía indiana que encontraba no sólo un campo lucrativo y mejores condiciones para negociar sus privilegios, sino una infraestructura territorial que garantizaría la retroalimentación de sus negocios.

\footnotetext{
74 Wasserman, 2020: 25.
} 


\section{Conclusiones}

A partir de la firma del Tratado de París en 1763 y la posterior restitución de las islas Malvinas a la monarquía hispánica en 1767, se produjo una rearticulación del espacio Atlántico meridional en la que el archipiélago constituyó una pieza fundamental de la estrategia imperial. El accionar inglés durante la Guerra de los Siete Años y su avance sobre los dominios españoles en América exacerbaron la importancia geopolítica de las islas Malvinas a escala global. Para desplegar sus propósitos defensivos en sus territorios australes, la Corona española dependió no sólo de su capacidad para movilizar los fondos de la Hacienda americana con fines defensivos, sino de los recursos financieros de los actores económicos rioplatenses. De esta manera, a partir de 1767 Buenos Aires se presentó como el eje articulador regional de una política imperial necesariamente imbricada en la escena local. El avance sobre Malvinas, la instalación de sus establecimientos y la consolidación de la colonia española en el archipiélago, dependieron de financistas locales que condicionaron la empresa imperial no sólo a cambio de réditos monetarios sino, igualmente, de reconocimiento institucional y fortalecimiento de sus redes de recursos relacionales.

En una valiosa investigación reciente, Barriera explica la centralidad que Malvinas comenzó a detentar en la estrategia política virreinal de Lima a partir de su restitución por parte de Francia, anudando en clave bioceánica las latitudes sudorientales del virreinato peruano con la capitanía general de Chile. Barriera demuestra la paradójica situación por la cual el virrey «tiene la información, tiene una posición, tiene la autoridad, pero no parece dispuesto a utilizarla, no parece de ninguna manera enfocado a dar una orden al capitán general y gobernador de Buenos Aires $\rangle^{75}$. El presente trabajo sugiere una arista posible para aportar respuestas a esa paradoja: afirmar la presencia española en Malvinas implicaba, a un mismo tiempo, articular su financiación con la oligarquía porteña, cuya participación en el patrimonio de la Hacienda redundaría en una mayor gravitación de Buenos Aires en el esquema interregional del gobierno de la Monarquía sobre el espacio peruano ${ }^{76}$. Dicha gravitación habría de traducirse institucionalmente menos de una década después.

La consecución del objetivo imperial se sustentó, por lo tanto, en los acreedores locales rioplatenses, cuya participación resultó condicionante para garantizar los recursos con los cuales la monarquía española custodiaría los mares y costas que procuraba conservar bajo su jurisdicción. Fue una conver-

75 Barriera, 2019: 65.

76 Wasserman, 2020: 37. 
gencia de intereses a escala local, con el corolario de un incremento de las tensiones a escala regional, la que garantizó el despliegue de la estrategia imperial.

\section{BiBLIOGRAFÍA}

Barriera, Darío, "Un rumor insistente. Saberes y circuitos de información para gobernar un archipiélago (las Islas Malvinas entre la Corte y el territorio, 17561767)", Diálogo Andino, 60 (Arica, 2019): 57-70.

Bayly, Christopher Alan, Imperial Meridian: The British Empire and the World, 17801830, Gran Bretaña, Routledge, 1989.

Bougainville, Louis-Antoine de, Voyage autour du monde par la frégate du roi "la Boudeuse" et la flûte "l'Étoile"; en 1766, 1767, 1768 \& 1769, París, Saillant \& Nyon, 1771.

Bougainville, Louis-Antoine de, Viaje alrededor del mundo a bordo de la fragata real la Boudeuse y la urca Étoile, en 1766, 1767, 1768 y 1769, Estudio preliminar, traducción y notas de Andrés Freijomil, Buenos Aires, EUDEBA, 2005 [1771].

Brewer, John, The Sinews of Power: War, Money, and the English State, 1688-1783, New York, Alfred A. Knopf, 1989.

Caillet-Bois, Ricardo (intr.), Colección de documentos relativos a la Historia de las Islas Malvinas, Buenos Aires, Universidad de Buenos Aires, Instituto de Historia Argentina Dr. Emilio Ravignani, 1957, tomo I.

Caillet-Bois, Ricardo (intr.), Colección de documentos relativos a la Historia de las Islas Malvinas, Buenos Aires, Universidad de Buenos Aires, Instituto de Historia Argentina Dr. Emilio Ravignani, 1961, tomos II y III.

Caviglia, Sergio Esteban, Malvinas: Soberanía, Memoria y Justicia: 10 de Junio de 1829, Rawson, Ministerio de Educación de la Provincia de Chubut, 2012.

Cuesta, Eduardo Martín, Precios, Población, Impuestos y Producción. La economía de Buenos Aires en el siglo XVIII, Buenos Aires, Temas, 2009.

Destéfani, Laurio, Historia naval argentina, Buenos Aires, Armada Argentina, 1970.

Fradera, Josep M., The Imperial Nation: Citizens and Subjects in the British, French, Spanish, and America Empires, Princeton / Oxford, Princeton University Press, 2018.

Gelman, Jorge Daniel, "El gran comerciante y el sentido de la circulación monetaria en el Río de la Plata colonial tardío", Revista de Historia Económica - Journal of Iberian and Latin American Economic History, 5/3 (Madrid, 1987): 485-507. 
Gelman, Jorge Daniel, "La economía de Buenos Aires", Raúl Fradkin (dir.), Historia de la Provincia de Buenos Aires. De la conquista a la crisis de 1820, Buenos Aires, UNIPE / Edhasa, 2012: 85-121.

González Enciso, Agustín, "El estado fiscal-militar, una reflexión alternativa", $M e$ moria y Civilización, 11 (Pamplona, 2008): 271-295.

Grieco, Viviana, La politica de dar en el Virreinato del Rio de la Plata. Donantes, prestamistas, súbditos y ciudadanos, Buenos Aires, Prometeo, 2019.

Groussac, Paul, Las Islas Malvinas, Buenos Aires, Comisión Protectora de Bibliotecas Populares, 1936.

Herrero Gil, María Dolores, "De las misiones guaraníticas al comercio de Cádiz: Francisco de Llano San Ginés o la acumulación originaria del capital", Naveg@ mérica. Revista electrónica de la Asociación Española de Americanistas, 10 (Murcia, 2013), https://revistas.um.es/navegamerica/article/view/171901

Irigoin, Alejandra y Grafe, Regina, "Bargaining for Absolutism. A Spanish Path to Empire and Nation Building", The Hispanic American Historical Review, 88/2 (Durham, 2008): 173-209.

Jiménez, Juan Francisco, Alioto, Sebastián Leandro y Villar, Daniel, Malvinas: hombres, ganados y tecnología rural criolla, siglos XVIII y XIX, Bahía Blanca, Editorial de la Universidad Nacional del Sur, Ediuns, 2018.

Kraselsky, Javier, Las estrategias de los actores del Río de La Plata: Las juntas y el Consulado de Comercio de Buenos Aires a fines del Antiguo Régimen 1748-1809, tesis de posgrado, Universidad Nacional de La Plata, Facultad de Humanidades y Ciencias de la Educación, 2011.

Luis XV (1710-1774, Rey de Francia), Traité de paix entre le Roi, le roi d'Espagne et le roi de la Grande-Bretagne, conclu à Paris le 10 février 1763. Avec l'accession du roi de Portugal, París, Imprimerie royale, 1763.

Marichal, Carlos y Grafenstein, Johanna von (coords.), El secreto del imperio español: los situados coloniales en el siglo XVIII, México, El Colegio de México / Instituto de Investigaciones Dr. José María Luis Mora, 2012.

Martínez, Carolina, "Revelaciones de un manuscrito francés sobre las islas Malvinas: Louis-Antoine de Bougainville en los contornos de la América hispana (1767)", Corpus [en línea], $7 / 2$ (Mendoza, 2017), http://dx.doi.org/10.4000/corpusarchivos. 1928

Mayo, Carlos, "Sociedad rural y militarización de la frontera en Buenos Aires, 1737 1810", Jahrbuch für Geschichte von Staat, Wirtschaft und Gesellschaft Lateinamerikas, 24 (Hamburg, 1987): 251-263.

Mououtkias, Zacarías, "Réseaux personnels et autorité coloniale. Les négociants de Buenos Aires au XVIIIe siècle”, Annales ESC, 4-5 (París, 1992): 889-915. 
Pardo de Guevara y Valdés, Eduardo (coord.), Actas de la XI Reunión Americana de Genealogía. España y América: un escenario común, Santiago de Compostela, CSIC-Instituto de Estudios Gallegos Padre Sarmiento / Xunta de Galicia, 2015.

Paredes, Rogelio, "Guerra en los libros. La competencia colonial del siglo XVIII entre Gran Bretaña y Francia en los libros del Museo Etnográfico de Buenos Aires (1690-1800)", Avances del Cesor, 8 (Rosario, 2011): 129-154.

Pernety, Antoine-Joseph, Historia de un viaje a las Islas Malvinas, Buenos Aires, EUDEBA, 2012.

Pincus, Steve y Robinson, James, "Faire la guerre et faire l'État: Nouvelles perspectives sur l'essor de l'État développementaliste", Annales. Histoire, Sciences Sociales, 71/1 (París, 2016): 5-36.

Rees Jones, Ricardo, El Superintendente Manuel Ignacio Fernández (1778-1783). Las reformas borbónicas en el Virreinato de Buenos Aires, Buenos Aires, Instituto de Investigaciones de Historia del Derecho, 1992.

Saguier, Eduardo, Un Debate Histórico Inconcluso en la América Latina (16002000). Cuatro siglos de lucha en el espacio colonial peruano y rioplatense y en la argentina moderna y contemporánea, Buenos Aires, Eduardo Saguier, 2004-2007, tomo IX, cap. 2, http://www.er-saguier.org/

Sandrín, María Emilia, "La actividad económica de los asentistas de víveres de la Marina de Montevideo, 1770-1810”, América Latina en la Historia Económica. Revista de Investigación, 21/1 (México, 2014): 92-114.

Solbes Ferri, Sergio, “Gasto militar y agentes privados. La provisión de uniformes para el ejército español en el siglo XVIII", Tiempos Modernos, 30/1 (Madrid, 2015): 9-18.

Solbes Ferri, Sergio, Dubet, Anne, Bertrand, Michel y Torres Sánchez, Rafael, “Actores políticos y actores privados en el gobierno de la Hacienda", Tiempos Modernos, 30/1 (Madrid, 2015): 1-8.

'T Hart, Marjolein, Pepijn, Brandon y Torres Sánchez, Rafael, “Introduction: maximising revenues, minimising political costs - challenges in the history of public finance of the early modern period", Financial History Review, 25/1 (Cambridge, 2018): 1-18.

Torres Sánchez, Rafael, “Administración o asiento. La política estatal de suministros militares en la Monarquía española del siglo XVIII”, Studia Historica: Historia Moderna, 35 (Salamanca, 2013a): 159-199.

Torres Sánchez, Rafael, El precio de la guerra. El Estado fiscal-militar de Carlos III, 1779-1783, Madrid, Marcial Pons, 2013b.

Torres Sánchez, Rafael, "El gasto público en la España del siglo XVIII", Ernest Sánchez Santiró (coord.), El Gasto Público en los imperios ibéricos, siglo XVIII, México, Instituto de Investigaciones Dr. José María Luis Mora, 2015: 23-72. 
Valle Pavón, Guillermina del, "Bases del poder de los mercaderes de plata de la ciudad de México. Redes, control del Consulado y de la Casa de Moneda a fines del siglo XVII", Anuario de Estudios Americanos, 68/2 (Sevilla, 2011): 565-598.

Valle Pavón, Guillermina del, Donativos, préstamos y privilegios. Los mercaderes y mineros de la ciudad de México durante la guerra anglo-española de 1779-1783, México, Instituto de Investigaciones Dr. José María Luis Mora, 2016.

Wasserman, Martín, "Recursos fiscales para administrar el Imperio. La gestión de los ingresos al ramo de Situados de Buenos Aires, 1766-1784", Estudios del ISHIR, 19 (Rosario, 2017): 82-115.

Wasserman, Martín, "Erogaciones fiscales, suministros militares y deudas. La distribución de los fondos del Real Situado en Buenos Aires entre 1766 y 1772", Anuario del Instituto de Historia Argentina, 18/2 (La Plata, 2018), https://doi. org/10.24215/2314257Xe075

Wasserman, Martín, "Crédito para la frontera. Negociación institucional, coerción militar y financiación de la Real Hacienda en el Río de la Plata borbónico (17671777)", Fronteras de la Historia, 25/1 (Bogotá, 2020): 8-44.

Zusman, Perla, “¿Terra Australis - «res nullius»? El avance de la frontera colonial hispánica en la Patagonia", Scripta Nova. Revista electrónica de geografía y ciencias sociales, 34/4 (Barcelona, 1999), https://raco.cat/index.php/ScriptaNova/ article/view/58729

Fecha de recepción: 19 de diciembre de 2019.

Fecha de aceptación: 4 de mayo de 2020.

\section{Imperial strategy and local credit. The Malvinas/Falkland Islands in the making of a Spanish frontier (1767-1774)}

This article investigates the role of the Malvinas/Falkland Islands in the reconfiguration of Hispanic American space since 1767. It articulates three variables of analysis: the geopolitical importance of the Malvinas/Falkland Islands on a global scale, their place in the redefinition of the Spanish monarchy's imperial frontier, and the role played by the economic actors of the Rio de la Plata in the colonization of the archipelago. Using political, cartographical and fiscal sources, this work demonstrates that the consolidation of borders - a necessity for the Monarchy-depended on a confluence of interests with local financial oligarchies.

KEY words: Malvinas/Falkland Islands; Spanish monarchy; geopolitics; finances; eighteenth century. 